\title{
O profissional da saúde e a sexualidade 4
}

Se considerarmos a saúde em seu sentido mais amplo, definida pela Organização Mundial da Saúde como o bem estar físico, psicológico e social, podemos considerar ser amplo o espectro de atividades profissionais que podem se encaixar nessa definição, sendo vistos como profissionais da área da saúde.

É fato reconhecido que a maioria dos cursos universitários existentes no país não preparam seus educandos das áreas afetas à saúde no que diz respeito ao exercício da sexualidade.

No caso dos médicos, são eles habitualmente adestrados apenas para conhecer sutis detalhes da reprodução, não constando do currículo qualquer instrução a respeito de desejo, padrões de conduta sexual ou mesmo informações sobre a fisiologia da resposta sexual humana. Essa falha, que não é sanada sequer na Residência Médica, faz com que nós médicos saibamos sobre sexo o que qualquer adulto medianamente instruído em outro ramo profissional sabe; a diferença é que seremos chamados, profissionalmente, a atuar nessa área.

* Ginecologista e Terapeuta Sexual. Doutor em Medicina pela USP. Presidente da Sociedade Brasileira de Estudos em Sexualidade Humana (SBRASH). 
O mesmo se pode dizer dos cursos de psicologia, que tampouco preparam os profissionais dele egressos para o atendimento direto dos problemas do exercício da sexualidade, pois quando enfocam a sexualidade, o fazem no que ela pode ter de distorcida e geradora de neuroses.

Em outros cursos, como os de enfermagem, pedagogia, promoção sociais e tantos outros, a falta de preparo é idêntica, sendo agravada, no caso dos profissionais das áreas afetas à educação, com a obrigatoriedade de lidar com a educação sexual.

Aliás, pode-se mesmo dizer que nossa falta de preparo é tanta, considerando-se apenas o que o comum dos cursos superiores ensina, que nem mesmo nossa própria sexualidade é melhor resolvida do que a de nossas pacientes. Temos as mesmas limitações e preconceitos machistas que a maioria do leigos.

No caso de profissionais de sexo masculino, a situação pode ficar ainda mais complicada, pois por vezes muitos não conseguem bem discernir que a admiração que as pessoas por nós assistidas nos devotam é fruto de uma idealização, e que elas vêem em nossa figura (imaculadamente vestida, bem barbeada, cheirosa, atenta e até carinhosa) um paradigma do homem que elas gostariam de ter como marido, ignorando nossas eventuais mazelas e maus hábitos, apenas supondo que não os temos.

Mesmo na situação inversa, de profissional de sexo feminino com clientela de sexo masculino, embora menos comumente, surgem também situações complicadas.

Dentro desse contexto, se o profissional não é emocionalmente maduro, é comum que, como maneira de exaltar seu ego, entre num perigoso jogo onde se misturam desejo e medo, num misto de ao mesmo tempo querer e temer seduzir e ser seduzido. Note-se que dentro do esquema social machista em que nossa sociedade está inteiramente imersa há aproximadamente 8.000 anos, somos todos homens e mulheres portadores de inúmeros preconceitos.

Dentro dessa linha machista de pensamento, é curioso registrar a observação pessoal, confirmada por muitos colegas médicos, de ouvirmos de nossas pacientes que nos elegeram (sendo homens) porque "não confiam em médicas mulheres”. É claro que para as colegas a situação não é muito diferente, pois o despreparo é comum a todos e o machismo é um preconceito que faz de todos nós, homens e mulheres, ao mesmo tempo suas vítimas e seus agentes.

Lembrar também, a título de complementação, que os profissionais da área de saúde, tanto orgânica como psicossocial, sempre foram usados pelos detentores do poder, como agentes repressores da sexualidade. É de todos conhecido o fato de terem sido publicados, no final do século passado e início do atual, inúmeros trabalhos e até Teses de Doutorado "provando", por exemplo, que a masturbação conduziria à loucura, além de causar tuberculose e idiotia. A sífilis, argumentava-se, é um castigo divino pela dis- 
solução dos costumes. Mesmo nos tempos correntes, as doenças transmitidas sexualmente, como a Síndrome da Imunodeficiência Adquirida, são claramente utilizadas para a repressão da sexualidade.

Assim, durante todo o curso universitário, a sexualidade é escamoteada. Ausente mesmo quando se fala em reprodução, fica-se com a impressão de que nós, humanos, praticamos reprodução assexuada. Eventualmente, se alguma coisa se diz a seu respeito, é para enfatizar os riscos e as conseqüência nefastas que sua prática pode trazer, como no estudo das doenças sexualmente transmissíveis. No entanto, sexualidade existe, e tem uma força biológica e social intensa, que se manifesta nas mais adversas condições. O profissional de saúde, por isso mesmo, deve estar alerta para bem orientar suas pacientes e os casais aos quais presta serviços, sobre temas ligados a essas manifestações.

Isso se torna ainda mais relevante nos casos de doenças graves, tais como o enfarte do miocárdio, por exemplo, ou de cirurgias, especialmente as ginecológicas, que pela sua própria natureza atingem órgãos diretamente ligados ao exercício da sexualidade como as perineoplastias, ou órgãos que de alguma forma simbolizam e sintetizam a própria essência da feminilidade, como o útero e a mama. Não nos esqueçamos de que não é por ter sido operada, por estar hospitalizada, por ter o colo de seu útero cauterizado ou por ser portadora de uma vulvovaginite, que nossas pacientes (e seus maridos!) deixam de ser criaturas sexualizadas.

Os profissionais da área (médicos, psicólogos, enfermeiras, educadores, assistentes sociais, etc.), para bem preparar-se para exercer adequadamente suas funções devem, qualquer que seja seu sexo, ter claramente resolvidas suas próprias limitações sexuais. O preparo técnico, escamoteado nos cursos universitários, tem que ser adquirido com esforço e sacrifício pessoais, através de leituras, cursos de extensão universitária e participação em sociedades dedicadas ao tema. O profissional consciente deve preocupar-se constantemente com a função sexual de seus clientes, mesmo quando não existem queixas ou referências explícitas a respeito.

Nas considerações que teceremos a seguir vamos nos deter mais especificamente nos ângulos da questão que dizem respeito às atividades de médicos e psicólogos, por serem estes a "tropa de choque" que suporta a emergência da maioria das queixas e referências de problemas afetos ao exercício da sexualidade, sendo além disso o foco maior de nossas atenções. Não perderemos de vista, no entanto, que preceitos e fatos similares ocorrem e devem ser observados também entre educadores, assistentes sociais, profissionais da área de enfermagem e outros.

\section{QUEIXAS SOBRE O EXERCÍCIO DA SEXUALIDADE}

O presente configura-se como um período muito peculiar na história da humanidade. Nunca, em todos os milênios sobre os quais temos notícias, 
foram re-discutidos os conceitos vigentes como na atualidade. A acentuada urbanização, a incrível penetração dos meios de comunicação de massa e a insegurança social e pessoal são marcas salientes de nossa vida neste findar de século, num nível de penetração nunca dantes experimentado.

Um dos mais consideráveis fatores de mudanças sociais tem sido a migração em massa da população rural para as áreas urbanas. Dados da Organização das Nações Unidas mostravam que, há escassos trinta anos, de cada 10 habitantes da América Latina, 7 residiam em zonas rurais ou em pequenos núcleos urbanos. Hoje a situação se inverteu e apenas 3 de cada 10 habitantes são ruralícolas, levando a um exacerbado crescimento urbano e tornando comuns as cidades com mais de 1 milhão de habitantes. Esse fenômeno de migração campo-cidade trouxe em seu bojo intensas modificações sociais, como a perda de raízes culturais, alterações de hábitos e costumes e mudanças na própria constituição do núcleo familiar. De fato, até os festejos de nossa tradição cultural tendem a desaparecer, substituídos por outros "importados" de outras plagas e difundidos pelos meios de comunicação. Nas cidades maiores, como São Paulo por exemplo, é mais fácil observar-se crianças brincando de "dia das bruxas", na americaníssima festa do "halloween", do que uma festa junina, por exemplo. Com a migração para as cidades, a própria composição das famílias mudou. Daquela família expandida de outrora, na qual múltiplas gerações com vários membros em cada uma habitavam o mesmo espaço, praticamente nada sobrou. A família atual, a família tipicamente urbana, é a chamada "família nuclear" que consiste num casal com um ou no máximo dois filhos. No ritmo acelerado da vida nas cidades, os membros dessas famílias quase não se vêem, perdidos que estão no trânsito, ou no trabalho o pai e quase sempre também a mãe, e nas escolas, nos cursos de judô, ballet ou natação os filhos. Os lares, longe de serem os pontos de reunião familiar de outras épocas, transformaram-se em verdadeiros acampamentos onde se vai comer (cada membro em um horário diferente), trocar de roupa ou dormir. A experiência dos membros mais idosos do "clã" familiar deixa assim de ser transmitida, substituída que é pelos conceitos e conhecimentos homogeneizados que os meios de comunicação transmitem. A introdução de uma escolarização cada vez mais precoce, com o uso quase obrigatório de Escolas Maternais, Jardins da Infância e Pré Escola, contribui para que cada vez mais as crianças recebam os conceitos sociais fora do lar. Essa perda de contato humano intra-familiar vem trazendo uma clamante modificação até mesmo no modo de viver das pessoas, em especial dos adultos. Temos cada vez mais conhecidos e cada vez menos amigos; torna-se comum que não saibamos sequer o nome do vizinho do apartamento ao lado, com o qual compartilhamos apenas e ocasionalmente, durante anos, um vago "bom dia" no elevador.

Não é nossa intenção de fazer juízos de valor ou mesmos julgamentos sobre essas mudanças, sequer afirmar que representam um avanço ou um retrocesso na conturbada história da humanidade; desejamos apenas regis- 
trar que elas existem e que são importantes do ponto de vista de costumes sexuais, que ora é nosso tema.

A insegurança pessoal e social, típica das grandes cidades de nossos dias, também contribui em muito para a sensação de vazio social, que freqüentemente observamos entre nossas pacientes. Medo de assaltos, medo dos mirabolantes planos econômicos dos nossos atuantes governantes, medo de contrair AIDS, medo de ser ou ter familiar raptado, medo de acidentes de trânsito, medo da degradação ambiental, medo de acidentes ou combates com armas atômicas, enfim, cada um de nós tem direito a cultivar dezenas de temores nos dias atuais. E sem dúvida esses temores, motivados ou não, direta ou indiretamente acabam influenciando o desempenho sexual de cada um de nós.

Os meios de comunicação de massa, por outro lado, alcançaram elevado grau de eficácia. Nesse aspecto particular, a televisão tem sido um fator importantíssimo na formação dos novos conceitos e hábitos de nossa sociedade. Claro que desde as pinturas rupestres das cavernas neolíticas sempre existiram meios de influenciar as pessoas. Foi com a vulgarização da televisão, entretanto, que esses meios se tornaram mais eficientes, a ponto de não sabermos mais hoje nem mesmo se escolhemos nosso creme dental usando nosso livre arbítrio ou porque a publicidade desta ou daquela pasta nos agradou e impressionou mais. Em termos de educação e orientação sexual os meios de comunicação têm se mostrado bastante atuantes. Desde programas de entrevistas na televisão até as revistas chamadas "femininas", a sexualidade é discutida e apresentada em diferentes graus de coerência e sensatez. Nas últimas décadas em especial tem-se apresentado uma imagem muito distorcida da sexualidade, que levam a crer ser o orgasmo a meta suprema da vida. Com isso, todos os outros aspectos do relacionamento humano e, em especial, do sexual, ficam prejudicados frente a "desgraça" que é para a mulher não conseguir ser multiorgásmica. Assim, quando se pergunta a alguma mulher se tem prazer no sexo, a inquirida responde sempre se tem ou não orgasmo; todo o resto do relacionamento (namoro, toque, carícias) é esquecido como fonte de prazer.

Soma-se a todos esses fatores a possibilidade que as mulheres tem alcançado neste final de século, ao menos em teoria, de maior possibilidade de expressar sua sexualidade. No discurso, liberal e liberalizante, as mulheres já estão se dando o direito de conquistarem prazer no sexo. Não é mais tão incomum quanto outrora que pacientes explicitem queixas referentes ao desempenho sexual, ainda que muito freqüentemente essas queixas venham disfarçadas no meio de outras, e raramente constituam o motivo declarado da consulta. Mesmo assim, entretanto, tem elas se tornado cada vez mais conspícuas. Em trabalho de nossa co-autoria, publicado em 1972, encontramos que mais de $60 \%$ das pacientes de um ambulatório de ginecologia apresentavam alterações de desempenho sexual, embora em apenas $2 \%$ das vezes a consulta tivesse essa disfunção como motivação primeira. 
Sem dúvida, se hoje repetíssemos essa mesma pesquisa o número de consultas explicitamente motivadas por problemas ligados à sexualidade seria maior. Duvidamos, entretanto, que representasse a totalidade dos casos, sendo ainda muitas das queixas disfarçadas entre as de um corrimento ou de uma dispareunia. É comum, por exemplo, que a mulher adie sua queixa sexual durante todo o decorrer da consulta, deixando para fazê-la quase que no momento de despedir-se. Tem-se a impressão de que a paciente vai postergando a apresentação do real problema que a levou à procurar o médico, enquanto toma coragem para fazê-lo.

Outras vezes, uma excessiva preocupação sobre a possível origem de um corrimento pode disfarçar o temor de ser ele de transmissão sexual e ocultar a culpa por uma relação extraconjugal, ou o receio de ter que admitir uma infidelidade praticada pelo marido.

Embora a maioria das pessoas ainda seja liberal apenas no discurso, podemos concluir que sem dúvida a atual fase de "liberação" dos costumes sexuais tornou, senão mais fácil, ao menos penoso às pacientes que exponham suas dificuldades diante de manifestações da sexualidade.

De qualquer maneira, porém, é importante que os profissionais da área de saúde, em especial médicos e psicólogos, se preparem para atendimento de problemas afetos ao desempenho sexual de seus ou suas pacientes, ou até mesmo do casal, pois explicitadas ou não essas disfunções existem, são freqüentes e relevantes.

\section{CONDUTA DURANTE A CONSULTA}

No caso específico dos médicos, é ainda discutido e discutível a forma como o profissional pode facilitar a formulação de eventuais queixas sexuais. Existem divergências de opinião sobre se deve ser provocado o surgimento de tais queixas ou se é melhor aguardar que elas surjam espontaneamente. É claro que num terreno movediço como é o da sexualidade devemos individualizar cada caso e, mais ainda, respeitar as limitações pessoais de cada um. Como norma geral, somos contrários a extensos e pormenorizados questionários sobre hábitos e desempenho sexual, especialmente na primeira consulta, a não ser que o ou a paciente declare explícita e espontaneamente ser a consulta motivada por uma queixa sexual. Nossa posição é alicerçada no fato de serem esses interrogatórios geradores de inibição e propiciarem, quase certamente, o surgimento de respostas inverídicas que tornarão mais difícil aos pacientes voltarem atrás mais tarde e contarnos seus reais problemas. Pessoalmente somos defensores da posição de que se deve deixar claro o fato de serem normalmente aceitas tais queixas, se existirem, e tentar mostrar-se o mais receptivo possível a qualquer fato ou emoção que eles queiram nos relatar. É muito importante fugir à emissão de juízos de valor, devendo o profissional constantemente lembrar-se não 
ser sua função julgar os atos ou os pensamentos de seus pacientes, mas sim orientá-los e auxiliá-los no que nos for possível.

$\mathrm{O}$ mesmo se diga para os atendimentos na área da psicologia, embora nesse caso específico as queixas acabem surgindo com mais facilidade. No entanto, importa lembrar que muitas vezes, por um processo de bloqueio ou similar, o próprio paciente não percebe a conotação entre suas queixas e os distúrbios sexuais.

Não queremos com isso dizer que somos contrários à formulação de perguntas de caráter eminentemente técnico, parte integrante de uma boa anamnese. Julgamos deverem elas serem feitas com a mesma naturalidade e constância com que fazemos aquelas referentes a outras funções. Assim, é imprescindível que se pergunte, dentro dessa linha, sobre fatos tais como a idade de início da vida sexual, o uso de métodos contraceptivos, a presença ou não de dispareunia, etc.

No que diz respeito da satisfação ou não quanto ao desempenho sexual, em uma primeira consulta costumamos dirigir apenas perguntas genéricas tais como: "Esta tudo bem com sua sexualidade?". Habitualmente, num primeiro momento, os pacientes quase sempre respondem que está tudo bem. Sentindo porém que não estão sendo julgados, trazem suas queixas, quando essas existem, ou no final da consulta ou em consultas subseqüentes, quando se sentem mais seguros e confiantes. Achamos que com perguntas genéricas como a que exemplificamos acima deixa-se aberto um importante canal de comunicação, por onde podem drenar as dúvidas e as angústias, sem o temor de reprovação explícita ou implícita. O importante é que o profissional esteja atento e seja receptivo a esse tipo de queixa, para que possa percebê-la e valorizá-la adequadamente.

Por vezes, devido a uma absoluta falta de preparo, é comum que os médicos, em especial os ginecologistas, tentem fingir que suas pacientes são seres assexuados, negando-se a perguntar ou até a ouvir dados referentes à atividade sexual. Essa conduta, absolutamente inadequada, demonstra em geral não apenas desconhecimento sobre a importância do tema, mas até mesmo dificuldades em lidar com a sua própria sexualidade.

Surgida uma queixa sobre a sexualidade, quer espontaneamente formulada quer não, fica para o profissional o problema sobre o que fazer com essa queixa. Devemos reconhecer que a maioria dos médicos e psicólogos, por estarem mal preparados para lidar com essa problemática, não conseguem tratar o tema de maneira adequada, mais freqüentemente encontrando tortuosos caminhos para dele fugir. $\mathrm{O}$ mesmo se diga de profissionais de outras áreas que, por desconhecimento pessoal sobre o tema em pauta, acabam colocando seus preceitos e preconceitos como expressão da mais pura verdade.

No caso específico dos psicólogos observa-se freqüentemente que o problema sexual é de tão urgente necessidade de solução que o ou a paciente não consegue se concentrar e motivar suficientemente para encarar o pro- 
cesso da terapia. Nesses casos, por serem os problemas sexuais tão relevantes em nossa cultura machista, é de pensar se o processo não seria melhor conduzido se o cliente for encaminhado primeiro a um terapeuta sexual, que levasse à remissão do sintoma, para depois propor-se um outro tipo de terapia, que propiciasse um tratamento do ou dos fatores causais. Aliás, a proposta da Terapia Sexual é exatamente esta, consistindo essa modalidade num conjunto de técnicas tiradas de várias correntes (psicanálise, comportamental, corporal, psicodrama, etc.) utilizadas no tratamento sintomático da queixa sexual.

Uma grande variedade de comportamentos pode ser observada, por parte dos profissionais, a maioria dos quais ineficazes, inadequados e indesejáveis. O mais comum é subestimar a queixa sexual, ora fingindo não ouvi-la, ora adiando seu parecer para depois daquele exame laboratorial urgente e imprescindível, ora afirmando paternalmente que a situação se corrigirá com o tempo. Outros, de conduta ainda mais danosa, opinam sobre o que não conhecem e dão "doutos" pareceres, como o absolutamente descabido "troque de parceiro", que já ouvimos referido por várias pacientes.

É também comum que, para "livrar-se" de um caso no qual não tem segurança para se conduzir, o profissional faça um encaminhamento apressado. Quando o paciente começa a se referir a qualquer fato que possa ter a aparência de uma queixa sexual, na ânsia de se livrar da situação embaraçosa, o médico o encaminha para um psiquiatra ou um psicólogo amigo, sem saber se o mesmo se dedica, com proficiência, à terapia sexual. Evidentemente pode-se e deve-se, em situações onde não temos segurança, encaminhar pacientes a outros colegas. No entanto, importa sempre lembrar o imenso custo emocional que significou para esse paciente armar-se de coragem e apresentar sua queixa e quanto de confiança está sendo depositada nesse médico, que sequer vai ouvi-lo e tenta transferir, numa penada, essa elaborada confiança a um outro profissional, absolutamente desconhecido.

Em nossa opinião, qualquer profissional pode e deve se capacitar para ajudar seus clientes na resolução de grande parte das disfunções sexuais, bastando para isso que saiba ouvir, que adquira os conhecimentos básicos indispensáveis e que se disponha a usar parte de seu tempo nesse mister.

Tratar ou não as disfunções sexuais deve ser uma escolha pessoal de cada um, como o é a opção de exercer qualquer outra subespecialidade dentro das tão vastas medicina e psicologia, pois nem todos temos formação, pendores e gosto para tratar esterilidade, ou depressões graves, fazer mastectomias ou microcirurgias tubárias. É, no entanto, obrigação de todo profissional conhecer o bastante sobre cada um desses itens para bem orientar sua clientela. Também no tocante à sexualidade, julgamos obrigatório que todos os médicos e psicólogos estejam preparados para saber ouvir, identificar e bem orientar suas pacientes, dentro de um esquema de conduta como o que descreveremos a seguir. 


\section{CONDUTA FRENTE ÀS QUEIXAS SEXUAIS}

\section{O preparo do profissional}

Em nossa maneira de entender, o problema deve ser abordado inicialmente sob o ângulo do preparo para o adequado atendimento na área da sexualidade. Como já dissemos acima (e julgamos que, como regra geral, a contestação é impossível), as Faculdades pouco ou nenhum preparo propiciam para condutas em temas multidisciplinares por excelência, como é o da sexualidade. Estuda-se a anatomia genital nas cadeiras de anatomia, mas sempre muito mais com um enfoque voltado para a reprodução do que propriamente para a sexualidade.

Os abundantes conhecimentos já disponíveis sobre a fisiologia e sobre os aspectos psicossociais da reposta sexual humana são solenemente ignorados em nossos cursos, que dedicam toda sua escassa carga horária a outros temas, considerados mais importantes.

Essa falha, insanável ao menos enquanto perdurar esse imobilismo que tem caracterizado as autoridades encarregadas de formular os currículos escolares, só pode ser compensada se o profissional, consciente dessa deficiência, esforçar-se e procurar, por mecanismos extra universitários, complementar sua formação. Para isso existem cursos de extensão, inúmeros livros e revistas especializadas, sociedades nacionais (como a Sociedade Brasileira de Estudos em Sexualidade Humana - SBRASH, por exemplo) e internacionais, conclaves e reuniões científicas em número e em qualidade suficiente para satisfazer a todos os paladares. É necessário, entretanto, que o próprio profissional reconheça a necessidade dessa complementação e se disponha ao dispêndio de tempo e de dinheiro necessários para realizá-la.

Parece-nos imprescindível que o profissional adquira conhecimentos sobre os aspectos sociais do exercício da sexualidade (educação sexual, machismo, papéis sexuais, etc.), além das suas facetas emocionais e orgânicas. É fundamental, no entanto, que tenha uma noção clara da fisiologia da resposta sexual humana, bem como de seus desvios, inadequações e disfunções, sem os quais não terá condições mínimas sequer para entender os problemas de seus pacientes, quanto mais para solucioná-los.

Somando-se a essa complementação teórica de conhecimentos sobre a sexualidade, é importante que médicos, psicólogos, educadores e outros profissionais da área da saúde se perguntem, com o maior grau de sinceridade possível, não só o que ele sabe ou deixa de saber sobre o sexo, mas também como ele lida com essas situações. Em outras palavras, como está ele em relação a sua própria sexualidade? É evidente que um profissional sexualmente frustrado e infeliz não tem condições de bem orientar sua clientela nesse tópico. 
Além disso, todos nós, profissionais ou leigos, em grau maior ou menor, carregamos uma série de preconceitos, que nos são inculcados na infância. Os preconceitos estão entranhados em nossa sociedade e vem sendo passados de geração em geração, alguns há milhares de anos. Todos nós, gostemos ou não, somos portadores desses preconceitos. Assim, é importante reconhecer que a afirmação "não tenho preconceitos", é inverídica e não traz qualquer benefício. Claro que todos nós, em graus variáveis, somos portadores de inúmeros preconceitos, em especial no que diz respeito à sexualidade, pois somos todos vítimas de um sistema educacional opressor. Preconceitos contra a homossexualidade, valores machistas, necessidade constante de auto-afirmação enquanto seres sexuados, para ficar apenas em alguns exemplos, são comuns a todos, homens e mulheres participantes de nossa cultura. O que devemos fazer é reconhecê-los e contra eles lutar, brava e continuamente. Não é incomum, por exemplo, que recebamos pacientes assumidamente homossexuais, que relatam terem sido escorraçadas, com maior ou menor diplomacia, da clínica de colegas ginecologistas mais "conservadores" (e quanto de preconceito se esconde sob essa palavra). No mínimo ouviam o chavão, prenhe de juízo de valor, “... mas minha filha, uma moça tão bonita como você...”.

Devem ser analisadas, intimamente ou em discussões com colegas mais experientes, posições pessoais sobre a fidelidade, a sexualidade de mulheres solteiras ou viúvas (principalmente as idosas), a masturbação e tantos e tantos outros assuntos afetos às manifestações da sexualidade. É óbvio que tal análise exige uma constante revisão de conceitos e de preconceitos, que durará provavelmente uma vida inteira.

Para as colegas, importa lembrar que o fato de serem mulheres não as torna mais conhecedoras dos temas ligados à sexualidade, nem as capacita mais do que os homens para lidar com este tipo de problema. Terão, certamente, mais facilidade para colher confidências e poderão talvez, por similaridade, melhor compreender as angústias vividas por suas pacientes. Para solucioná-las, entretanto, devem buscar preparar-se, tanto quanto seus colegas de sexo masculino, pois como já foi dito, estamos todos imersos no mesmo mar de preconceitos e somos todos vítimas do mesmo sistema educacional repressor e mal orientado.

\section{Iatrogenicidade}

O risco mais temível, no que tange à posição dos profissionais frente à sexualidade dos pacientes, é o de iatrogenização. O profissional deve estar atento para o fato de que suas palavras tem, para quem a ele recorre, o peso da verdade insofismável. Por isso mesmo, é de extrema importância que fujam de observações apressadas ou preconceituosas e que estejam realmente preparados para atender essa demanda, assumindo a postura humilde, quando necessário, de confessar desconhecimento sobre certos temas, 
propondo-se a buscar com outros as respostas que seus pacientes lhe pedem. A conduta oposta, quando o profissional não tem esse nível de consciência, é de transformar seus preconceitos em verdades cientificamente aceitas, assim passando-as aos seus clientes. Lembremo-nos do risco de iatrogenização provocada por atos, postura corporal, gestos ou até mesmo por expressões fisionômicas inadequadas.

Parece-nos evidente que a opinião ou mesmo a postura do profissional se reveste de particular importância para os pacientes, visto ter sido ele eleito para depositário de suas dúvidas, queixas e esperanças. É fácil entender, por isso, que qualquer passo em falso, qualquer conduta inadequada assumida possa não apenas deixar de resolver o problema como até mesmo agravá-lo ou criar novos conflitos. É importante que se frise ter a figura que o profissional representa, nesse particular, uma importância ímpar e que um descuido ou um erro podem ter conseqüências irreversíveis na vida dos pacientes.

1. Encarar com menosprezo, dando pouca importância às queixas e dúvidas expressas.

Os pacientes ou os educandos, nessa situação, evidentemente vão raciocinar que se esse profissional, eleito entre tantos outros, julga que se essa queixa, dúvida ou angustia não tem a menor importância, devem mesmo serem neuróticos irrecuperáveis. Voltemos a lembrar que, para a maioria das pessoas, não é fácil elaborar e criar coragem de expressar algumas dessas dúvidas ou queixas, mas pelo contrário, o comum é que o sejam no final de um trabalhoso e duro processo. Por isso mesmo, devemos dar a elas ao menos tanta importância quanto os próprios portadores lhes atribuem.

2. Uso de uma pretensa incapacidade ou inferioridade sexual específica como forma de fugir ao problema.

É o caso, por exemplo, de afirmações do tipo "mulher é assim mesmo", ou "é normal que as mulheres honestas não tenham orgasmos", que são relativamente comuns como forma de fugir a discussão do assunto, numa postura obscurantista e machista, que se constitui claramente um subterfúgio utilizado pelo profissional para fugir da discussão de um tema que ele não domina.

\section{Fornecer informações sem base científica.}

Nossos clientes vêem em nós profundos conhecedores dos mais íntimos mecanismos biológicos e nos prestam um crédito ao qual, lamentavelmente, muita vezes não fazemos juz. Para eles, de uma maneira geral, tudo o que dissermos será interpretado como a mais pura expressão da verdade. É fácil assim avaliar quanto dano podemos causar, se disfarçarmos nossos preconceitos em verdades científicas. Se isso é válido para qualquer tema, o é ainda mais nos assuntos ligados à sexualidade, no qual nossos pacientes 
nos consideram grandes "experts". O profissional mal preparado, sem conhecimentos científicos atualizados, tende a se convencer, por tortuosos caminhos, da veracidade de afirmações preconceituosas, passando-as para os pacientes como uma verdade científica indiscutível.

\section{Propor tratamentos sem bases científicas.}

A variedade dessas formas de iatrogenização é imensa, indo desde plásticas perineais desnecessárias "para melhorar o desempenho sexual" ou mesmo "para satisfazer o marido", até os alongamentos do pênis, cirurgias para o tratamento da ejaculação precoce e tratamentos com placebos ou com os hormônios os mais diversos. Capítulo a parte tem sido a indicação abusiva e mercantilista de próteses penianas para homens com disfunções psicogênicas ou até com ausência de desejo. Recentemente, ainda que não exista qualquer evidência nem caminho lógico pelo qual o Sildenafil possa obter bons resultados entre mulheres (sequer o Laboratório fabricante da droga tem a pretensão de indicá-la para mulheres), tem ele sido prescrito para qualquer disfunção sexual feminina, evidenciando a falta de conhecimentos na farmacologia da droga por parte da maioria dos clínicos.

É o caso ainda, dentro desse mesmo item, de colegas que se dispõem a fazer terapia sexual para pacientes ou casais disfuncionais, baseado apenas em métodos de que ouviu falar em cursos intensivos de apenas algumas horas, ou sobre os quais leu em alguma revista ou livro médico. Importa frisar, ainda que isso possa parecer desnecessário, que a formação de um terapeuta sexual é tão árdua e exige tanto esforço e tempo quanto a de qualquer outra área. Aventuras pessoais nesse sentido são totalmente condenáveis.

\section{Sugestões de procedimentos esdrúxulos.}

Baseados talvez em problemas pessoais, não é raro ter-se notícia de que colegas recomendaram, como forma de resolver problemas ligados à sexualidade, condutas pouco ortodoxas e completamente fora da sua área de conhecimento, tais como a separação conjugal ou "arranjar um amante". Pode parecer chocante, mas conselhos tão absurdos quanto esses são dados com muita freqüência.

\section{O uso da sexualidade do próprio profissional.}

Esse é o grau máximo da iatrogenização. Emocionalmente imaturo, com sua própria sexualidade mal resolvida e necessitando de constantes auto afirmações de sua virilidade, algumas vezes o próprio médico ou psicólogo se insinua como sendo o parceiro sexual que pode resolver os problemas de pacientes. Estes, emocionalmente instáveis e regredidos pela própria existência do problema, podem em algumas situações serem presa fácil para esse tipo de "terapeuta".

É claro que essa relação é altamente patogênica, tendo em vista que nenhum dos dois chega a pesar maduramente as conseqüências desse ato, 
que com quase certeza será danoso e trará sérios danos a ambos, mas mais facilmente evidenciáveis nos pacientes.

\section{A conduta adequada}

Mais uma vez nos referiremos especificamente a médicos e psicólogos, embora os princípios gerais aqui exarados possam ser adaptados à atividades profissionais de educadores, assistentes sociais, profissionais de enfermagem e outros.

Listaremos a seguir os passos que podem e devem ser tomados frente às dúvidas e queixas sexuais. Julgamos obrigatórios alguns passos para todos os profissionais das áreas médica e psicológica (a, b, c); outros, obrigatórios para os médicos (d). O quinto passo (e), é uma possibilidade para médicos ginecologistas. $\mathrm{O}$ último passo (item $\mathrm{f}$ ), que envolve a decisão de exercer a terapia sexual ou encaminhar a paciente a quem a faça, vai depender das tendências de cada profissional, tanto da área médica quanto da psicológica.

\section{a) Abrir espaço para um ouvir atento e interessado}

Como já dissemos na introdução ao tema, é imprescindível que o paciente possa sentir-se à vontade para fazer qualquer pergunta, esclarecer qualquer dúvida ou apresentar qualquer queixa, sem que seja por isso julgado ou censurado. Dissemos também que nossa opinião pessoal, no caso dos atendimentos médicos, é de que deva ser feita apenas uma pergunta genérica sobre a sexualidade dos pacientes, mais no sentido de que fique claro que esse espaço existe.

Desde que a dúvida ou a queixa surgiu, espontaneamente ou não, é fundamental que o profissional ouça atentamente. Esse "ouvir ativo" implica em acompanhar com interesse, dirigir perguntas, solicitar esclarecimentos, enfim, reunir todas as informações possíveis sobre a época e sobre as condições de surgimento da dúvida ou da disfunção.

\section{b) Caracterizar exatamente o problema}

Dentro do verdadeiro analfabetismo sexual em que a maioria das pessoas em nossa sociedade está imersa, nem sempre é muito fácil que se compreenda exatamente qual a dúvida ou o problema apresentado pela paciente. Como qualquer tratamento ou orientação depende de um entendimento perfeito da situação, sua exata caracterização é imprescindível.

Para bem conseguir compreender a situação, a coleta de dados deve reunir, entre outros dados de importância:

* História pessoal: como foi a educação sexual do paciente e de que maneira adquiriu os conhecimentos atuais sobre a sexualidade, eventuais episódios de vitimização sexual, como ocorreu a iniciação sexual e se ocorreram relações sexuais pré conjugais, dentre outras informações relevantes. 
* História conjugal: firmeza do vínculo afetivo com o parceiro, dificuldades sexuais ou extra sexuais no relacionamento e sentimentos em relação a ele.

* Relacionamento atual: avaliação do desempenho sexual do parceiro, prática de jogos amorosos pré coito e local em que ocorrem as relações.

Não é incomum que ouçamos queixa vagas como "sou fria", onde é absolutamente necessário caracterizar se a disfunção é de desejo, de excitabilidade ou de orgasmo. Em certas situações, até quem é o real portador de um problema pode ser difícil de caracterizar, não sendo incomum que homens com ejaculação precoce acabem convencendo suas esposas de que elas é que demoram demais para atingir o orgasmo. Evidentemente, se a queixa não ficar bem caracterizada, será muito difícil estabelecer-se uma linha propedêutica ou terapêutica adequada.

Outras vezes a queixa tem matizes situacionais bem marcados. Situações curiosas, dificuldades sociais ou até problemas econômicos podem ter repercussão sobre a esfera da sexualidade. São casos por exemplo de pacientes que residem com outras pessoas da família e reprimem manifestações de sua sexualidade por medo de serem ouvidas em outro cômodo da casa, ou de maridos que, perdendo o emprego e em dificuldades econômicas, tornam-se alcoólatras indesejáveis ou disfuncionais sexuais por angústia.

Detalhes como se a paciente atinge o orgasmo durante a masturbação ou não, podem afastar um fator orgânico como causa de disfunção orgásmica. $\mathrm{O}$ fato de ter excitação e orgasmo com um parceiro e não com outro, pode indicar uma disfunção situacional. Enfim, cada detalhe da queixa pode ter importância na caracterização do problema e, portanto, no sucesso de sua resolução.

\section{c) Orientação e esclarecimento de dúvidas}

É absolutamente necessário que o profissional reuna os conhecimentos em fisiologia da sexualidade necessários para bem orientar e esclarecer as dúvidas de seus pacientes. Muitas vezes, com uma simples explanação resolve-se o que parecia aos clientes uma terrível disfunção sexual. Principalmente nesta época, em que os meios de comunicação divulgam conceitos fantasiosos sobre a sexualidade, somos por vezes consultados para resolver problemas tais como o de uma paciente que se julgava anormal por ter apenas um orgasmo por relação, ou a freqüente situação em que o homem julga seu pênis pequeno, o que impediria, em sua fantasia, que suas parceiras chegassem ao orgasmo. São comuns questões relativas à normalidade ou não de certos atos eróticos, como o coito anal, por exemplo, que despertam profundas sensações de culpa. Enfim, perguntas que podem nos parecer banais muitas vezes trazem em seu bojo grandes conflitos íntimos, a empanar a plena realização sexual dos casais. 
Tem sido comum também que sejam trazidas a médicos, psicólogos e educadores questões relativas à normalidade ou não de manifestações da sexualidade de filhos ou de outros parentes, ou ainda dúvidas sobre como proceder frente a certas situações ligadas à educação sexual de crianças e adolescentes.

Em termos de orientação aos filhos, devemos esclarecer os nossos pacientes as causas sociais do comportamento familiar e social de expectativa frente ao comportamento dos filhos de sexo masculino e feminino. Condutas frente a temas como masturbação devem ser discutidas com o máximo de profundidade possível, sendo sempre necessário que se tome o cuidado de não tentar impor nossos próprios valores aos pacientes.

Fazem parte obrigatoriamente dessa orientação discussões sobre aspectos da fisiologia da resposta sexual humana, a desmistificação do orgasmo como meta suprema de todo relacionamento, informações sobre variações sexuais e sobre a sexualidade nas diversas fases da vida. Os pacientes devem ser estimulados a manter um diálogo franco e aberto com seus ou suas companheiros ou companheiras, sobre o que ambos gostam e sobre o que não gostam, tendo sempre como norma que um relacionamento só tende a se solidificar quando baseado na verdade.

Em situações especiais, o profissional deve estar suficientemente atento para responder até mesmo a perguntas não formuladas e a orientar pacientes em aspectos ligados a sexualidade. Nos casos em que é impositiva a abstenção de relações sexuais, prescrita por motivos médicos, frente a um abortamento evitável ou após uma cauterização de colo, por exemplo, é fácil referir essa proibição ao casal; mas e as alternativas, são permitidas? $\mathrm{O}$ casal pode, por exemplo, praticar a masturbação mútua? E quando, no puerpério, se pode reiniciar a vida sexual ativa? Por isso, nessas e em muitas outras situações é importante que o médico lembre-se sempre de que está tratando de seres sexuados, com desejos, fantasias e necessidades sexuais e afetivas que não podem ser esquecidas. Existem outras situações em que a paciente ou o casal desejam assumir a culpa pelo que julgam ser as conseqüências danosas de um ato sexual. Afirmar, por isso, clara e firmemente à paciente que seu abortamento não foi causado por aquela relação sexual é uma necessidade, para que a mulher não carregue pelo resto de sua vida a culpa por esse episódio, o que sem dúvida poderá gerar uma disfunção sexual futura.

Outro aspecto importante da atuação específica do ginecologista ou do urologista sobre a sexualidade do casal surge quando, numa investigação ou num tratamento de esterilidade conjugal, faz-se necessário recomendar ao casal que tenha uma relação sexual num determinado momento, para um teste pós-coito ou que o marido vá a uma determinada sala de laboratório masturbar-se para um espermograma. É claro que não apenas a necessidade do procedimento deve ser muito claramente explicada, mas também que se deixe claro ser compreensível a dificuldade existente para que as 
pessoas consigam se excitar nessas circunstâncias. Se isso não for muito bem esclarecido, poder-se á passar ao casal que qualquer dificuldade que eles venham a apresentar é anormal. Já ouvimos chorosas pacientes declararem-se pouco atraentes por que seus maridos não conseguiram se excitar o suficiente para cumprir as determinações de esterilêuta, que recomendou ao casal manter relações em determinados dias e horários.

Item da máxima importância para os médicos, infelizmente raras vezes observado, é a orientação sobre as influências de determinadas intervenções no exercício da sexualidade, tais como cirurgias, cauterizações, ou mesmo o simples uso de um creme vaginal. Obviamente é sempre mais fácil e menos arriscado proibir aos pacientes a vida sexual ativa no pósoperatório ou mesmo no intra e pós-tratamento, por um prazo o mais prolongado possível. Tal conduta, no entanto, é incorreta e pode ser danosa para o relacionamento do casal. É relevante, para o médico consciente e atuante, que se informe sobre os efeitos da vida sexual ativa nessas situações e não que simplesmente a proíba, por ignorância ou para fugir da responsabilidade de assumir uma permissão.

Enfim, deve o profissional estar preparado não só para toda a orientação de que for capaz, mas também para confessar suas dúvidas ou falhas de conhecimento, quando for o caso. A postura absolutista do "eu sei tudo" é extremamente perniciosa e, mais cedo ou mais tarde, desmoralizante. Não deve ser encarada como uma grave e inadmissível falha, confessar a um paciente que temos dúvidas ou que não estamos suficientemente seguros em determinadas situações; pelo contrário, ao admitir que não sabe mas que procurará se informar, o profissional estará dando um exemplo de coragem e de grandeza de alma que certamente seus pacientes saberão apreciar.

d) Procurar e tratar causas orgânicas (item específico para os médicos)

É da intransferível competência do médico, em especial de ginecologistas e urologistas, o diagnóstico e o tratamento de fatores orgânicos de disfunção sexual. Embora as causas psicogênicas, principalmente aquelas advindas de um sistema educacional repressor e massacrante da sexualidade, sejam fatores muito comuns na gênese da disfunção sexual, é imprescindível que o especialista tenha conhecimentos para caracterizar patologias somáticas que interfiram na resposta sexual. Além de inútil e contraproducente, nada mais descabido do que encaminhar à psicoterapia um paciente que faz uso de drogas depressoras da sexualidade, por exemplo, ou outra que apresente dispareunia por anexite crônica.

O próprio fato de não ter sido encontrada qualquer causa orgânica que possa desencadear uma disfunção sexual pode ser de importância, pois permitirá ao clínico reafirmar a normalidade física de sua paciente. 
e) Tratamento do vaginismo (facultativo aos ginecologistas)

Embora tendo como fatores causais eventos de cunho psicológico, o vaginismo se reveste de um caráter especial, sendo uma disfunção sexual específica. O tratamento é de aprendizado simples e ao alcance de qualquer ginecologista, visto que não requer técnicas elaboradas de terapia sexual. Em nossa maneira de entender, todos os ginecologistas deveriam se preparar para atender esses casos, pois o tratamento proposto pelo ginecólogo é sabidamente mais eficiente do que a própria terapia sexual.

$\mathrm{O}$ tratamento é habitualmente simples e seguro, consistindo basicamente na demonstração de que a penetração vaginal não é obrigatoriamente dolorosa. Tal tratamento, que evidentemente deve ser acompanhado de uma forma associada de psicoterapia, pode perfeitamente ser empreendido por ginecologistas.

A expressão mais simples desse tratamento é a introdução vaginal, sob visualização direta da paciente, de objetos com calibres cada vez maiores, culminando num exame ginecológico completo, com a introdução de um espéculo vaginal. Paralelamente a essa prática, deve-se fazer uma terapia de apoio ao casal.

\section{f) Tratar ou encaminhar as disfunções sexuais psicogênicas}

Cumpridos os primeiros pontos do programa que ora estamos propondo e que julgamos obrigatórios para todos os profissionais e afastado qualquer fator de fundo orgânico, chegamos ao passo seguinte, que é o de tratar uma disfunção psicogênica ou orientar a paciente para outro profissional. Deve-se frisar mais uma vez que muitas das queixas sexuais, mesmo as de caráter psicossocial, podem e são resolvidas com os passos até aqui enumerados.

No entanto, se a simples orientação não é capaz de corrigir o problema e, tendo sido afastada de forma insofismável ou tratada uma possível causa orgânica ele ainda permanece, fica patente a necessidade de um processo psicoterápico.

Por serem os problemas ligados à esfera sexual extremamente angustiantes e geradores de depressão, principalmente num meio como o nosso, em que homens e mulheres só assim se consideram se forem sexualmente competentes, as técnicas psicoterápicas tradicionais não são, isoladamente, adequadas. De fato, propor-se a um angustiado homem impotente um tratamento que possivelmente resolverá seu problema dentro de alguns anos, não é muito animador. Tem sido por isso preferida nessas indicações a denominada "terapia sexual", que consiste em um conjunto de técnicas breves de terapia, baseadas fundamentalmente na terapia comportamental, com acréscimos tirados de outras correntes (psicanálise, psicodrama, técnicas corporais, etc.). Tais técnicas podem ser, quando julgado necessário, complementadas com práticas psicoterápicas mais aprofundadas. Os profissionais que se dedicam a essa denominada Terapia Sexual podem ser 
provenientes das áreas psicológica ou médica. Dedicar-se a essa atividade, voltamos a repetir, é uma opção de cada um, nada havendo de desdouro em encaminhar tais pacientes a um profissional competente.

Deve então o profissional resolver como esse passo será dado. Caso opte por exercer a terapia sexual, é obrigatório que para isso se prepare, visto ser inegável que nem os cursos universitários nem os estágios ou Residências Médicas são competentes para formar profissionais nessa difícil área.

A alternativa para os que não desejam ou não sentem em si inclinações para tais práticas, é o encaminhamento da paciente a algum terapeuta sexual competente. Lembremos, mais uma vez, que psicoterapeutas competentes em outras áreas, nem sempre o são na terapia sexual. Por isso, é necessário que o profissional, antes do encaminhamento, conheça os profissionais bem preparados que atendem em sua região, para a eles referir adequadamente suas pacientes.

Importa frisar que o profissional, mesmo quando encaminha uma paciente a um terapeuta de sua confiança, não pode nem deve deixar de se interessar pelo caso, procurando se inteirar da evolução do tratamento e acompanhando sua solução, ainda que à distância.

\section{BIBLIOGRAFIA RECOMENDADA}

CANELLA, P. R. B. O médico como controlador da sexualidade. RBSH, 2:133, 1991.

FALCONET, G. \& LEFAUCHEUR, N. A fabricação de machos. Ed. Zahar, Rio de Janeiro, 1977.

GOUVEIA, M. H. A influência dos meios de comunicação no desenvolvimento da sexualidade humana. RBSH, 1:1, 1990.

KUSNETZOFF, J. C. Crises e ajustamento na relação do casal. Sexus, 2(4):5, 1990.

LUZ, H. S. O clínico diante da sexualidade. Selecta, 9(2):31, 1986.

NAHOUM, J. C. A masturbação nas teses da Faculdade de Medicina do Rio de Janeiro no século XIX. Sexus, 3(1):16, 1991.

RODRIGUES JR., O. M. et al. $O$ ginecologista brasileiro e a sexualidade humana. II Abordagem da sexualidade da paciente. Reprodução, 3:235, 1987.

RODRIGUES JR., O. M. A opinião do ginecologista sobre a homossexualidade e bissexualidade. Sexus, 2(3):15, 1990.

SAFFIOTTI, H. I. B. O poder do macho. Ed. Moderna, São Paulo, 1988.

SILVEIRA, M. T. O ginecologista e a paciente disfuncional. RBSH, 3:23, 1992.

VALADARES, N. A condição feminina. Ed. Revista dos Tribunais, Edições Vértice, São Paulo, 1988.

VIEZZER, M. O problema não está na mulher. Ed. Cortez, São Paulo, 1989.

VITIELLO, N. Resposta sexual humana. Femina, 17:917, 1989.

VITIELLO, N. Quem educa o educador. Iglu, São Paulo, 1997. 
VITIELLO, N.; CUNHA, A. C. M.; VERRONE, M.; VITIELLO, M. T. Distúrbios da libido e do orgasmo. G.O., 6(12):27, 1972.

VITIELLO, N. \& CONCEIÇÃO, I. S. C. O exercício da sexualidade na adolescência. RBSH, 1(2): $15,1990$.

VITIELLO, N. \& RODRIGUES JR., O. M. As bases anatômicas e funcionais da Sexualidade humana. Iglu, São Paulo, 1997. 